\title{
AROMATIC PLANTS FROM VIETNAM, SOURCES OF PHENYLPROPANOID PRODUCTS FOR INDUSTRY
}

\author{
Tran Minh Hoi* \\ Institute of Ecology and Biological Resources (IEBR)
}

Received 27 August 2005

\begin{abstract}
Aromatic plants produce by vapour distillation or other processes essential oils which are products with high commercial value used in the natural product industries such flavour and fragrance, perfumes and cosmetics industries as well as pharmaceutical industry. The aim of this study was to characterise some aromatic plants from Vietnam through the chemical composition of their essential oils. We got interested in essential oils which contained a main component with high to ultra high content, susceptible to find an industrial use. For this study, a dozen of plants have been selected. The composition of their essential oils will be compared with those of the same plants, reported in the literature, from Vietnamese origin or from other countries.
\end{abstract}

Keywords: Vietnam, Aromatic Plants, Essential oils, Agastache rugosa (Fisch. et Mey.) Kuntze, Cinnamomum cassia Presl., Illicium verum Hook. f., Kaempferia galanga L., Ocimum gratissimum L., Michelia balance (DC) Dandy, anethole, (E)-cinnanlaldehyde, Ethyl pmethoxy-(E)-cinnamate, eugenol, estragole, safrole.

\section{INTRODUCTION}

Essential oils are obtained by water distillation or vapour distillation of the whole plant or part of the plant (aerial parts, leaves, flowers, fruits, seeds, stems, wood, roots). They are, in general, complexes mixtures of several tens and sometimes more than one hundred components, present in variable proportions. The components are, most of the time, terpene hydrocarbons or oxygenated terpenes containing 10, 15 and scarcely 20 atoms of carbon (mono, sesqui and diterpenes), bearing very diverse skeleton, acyclic, cyclic, bicyclic, polycyclic (eventually bridged) and functionalities, olefins, alcohols, aldehydes, ketones et esters. Phenylpropanoids may be observed as well as linear non terpenic compounds. However, a few essential oils contain a main component which is by far the most important and could constitute an industrial source of this natural compound. Such essential oils, with high commercial value, could be of interest for natural product industries such flavour and fragrance, perfume and cosmetic industries as well as pharmaceutical industry.

The world annual production of essential oils was estimated to 45000 tons which represented in the early nineteen's a value of 700 millions of US dollars. The essential oils, which are obtained without the use of solvent or reactant are free of chemical pollution. Moreover, in most cases, the plant produces a single enantiomer of a molecule, enantiomer which possesses specific olfactory or pharmaceutical properties.

\footnotetext{
* Corresponding author e-mail: tranhoi@iebr.ac.vn
} 
This study was achieved in the course of an important work concerning the characterization of aromatic plants from Vietnam through the chemical composition of their essential oils. We got interested in essential oils which contained a main component with high to ultra high content, susceptible to find an industrial use. For this study, six plants have been selected. The composition of their essential oils will be compared with those of the same plants, reported in the literature, from Vietnamese origin or from other countries.

\section{RESULTS}

Among the numerous plant of Vietnamese origin we have investigated within a research program sponsored by the French Ministry of Foreign Affairs and the Collectivite Territoriale de Corse, we have selected a dozen of aromatic plants which produce an essential oil dominated by a single component. The content of that compound in the oil may be high, very high or extremely high, and consequently, the essential oil could be a source of this compound for the industry of natural products.

The essential oils of six aromatic plants contained mainly a component bearing the phenylpropanoid framework. This compound is:

- $\quad$ Anethol in the oil from star anis, Illicium verum Hook. f.,

- Estragole in the oil from Agastache rugosa (Fisch. et Mey.) Kuntze,

- Eugenol in the oil from Ocimum gratissimum L.,

- $\quad$ Safrole in the oil from Michelia balance (DC) Dandy,

- (E)-cinnamaldehyde in the oil from Cinnamomum cassia Presl.,

- (E)-ethyl cinnamate and (E) para-methoxy-ethyl cinnamate in the oil from Kaempferia galanga $\mathrm{L}$.

Although, in the course of this program, we have analysed several samples of essential oil extracted from the investigated plants, we only report in the table below the chemical composition one sample. The chemical structures of the main compounds are reported in the Figure 1.

\subsection{Illicium verum Hook. f. (star anis) essential oil, source of (E)-anethole}

Illicium verum (star anis) is widely cultivated in Vietnam and used as medicinal plant. The analysed sample contained $93 \%$ of (E)-anethole [synonym (E)-1-methoxy-4-(1-propenyl)benzene; (E)-4-(1-propenyl)-anisole] and $2.5 \%$ of limonene, the single one other compound present at noticeable content. Anethole is widely used in the production of fragrances and it is particularly present in soaps and in cleaning materials. The (E) isomer is rather used as floral base in the products intended for fine perfumery. Essential oil of Illicium verum possess an interesting antimicrobial activity, specially induced by the presence of anethole. The content of (E)-anethole in this sample is very high, compared to those reported in the literature and reviewed by Lawrence: $71-78 \%$ for the oils from China in which the major compound is present with another oxygenated compound as anisaldehyde, estragole or foeniculine; $88 \%$ for samples from unspecified origin.

\subsection{Agastache rugosa (Fisch. et Mey.) Kuntze essential oil, source of estragole}

Agastache rugosa from Lamiaseae. The investigated sample contained $96 \%$ of estragole [synonym = 1-methoxy-4-allylbenzene, 4-allylanisole, methylchavicol]. It possess an herbaceous odour slightly similar to that of anis and it is used for the preparation of synthetic 
oils such as estragon oil. The chemical composition of this sample is close to that reported by Dung et al in which the content of estragole varied from 76 to $92 \%$, according to the part of the plant. It seems that the chemical composition of the essential oil of Agastache rugosa from Vietnam is more homogeneous than that reported by Fujita (estragole and methyleugenol : 83 $92 \%$ ) or by Svoboda et al (estragole and menthone and/or isomenthone, plant cultivated in Scotland) and is quite different to that reported by Lawrence (isomenthone 10-57\%, pulegone 9$52 \%$, plant cultivated in North Carolina).

Table 1: Chemical composition of phenylpropanoid rich oils from Vietnam, (samples 1 - 6).

\begin{tabular}{|c|c|c|c|c|c|c|c|}
\hline Components & RI & 1 & 2 & 3 & 4 & 5 & 6 \\
\hline$\alpha$-pinene & 931 & - & - & - & 1,4 & - & - \\
\hline$\beta$-pinene & 972 & - & - & - & 3,0 & - & - \\
\hline limonene & 1021 & 2,5 & 1,8 & - & 4,8 & - & - \\
\hline (E)- $\beta$-ocimene & 1024 & - & - & - & 1,4 & - & - \\
\hline linalool & 1081 & - & - & - & 1,4 & - & - \\
\hline estragole & 1124 & - & 96,2 & - & - & - & - \\
\hline borneol & 1149 & - & - & - & - & 0,4 & 3,1 \\
\hline (E)-cinnamaldehyde & 1236 & - & - & - & - & 92,4 & - \\
\hline safrole & 1262 & - & - & - & 84,5 & - & - \\
\hline (E)-anethole & 1268 & 93,1 & - & - & - & - & - \\
\hline cinnamyl alcohol & 1270 & - & - & - & - & 0,4 & - \\
\hline eugenol & 1337 & - & - & 82,7 & - & - & - \\
\hline$\alpha$-copaene & 1379 & - & - & 1,7 & - & - & - \\
\hline coumarin & 1388 & - & - & - & - & 0,7 & - \\
\hline cinnamyl acetate & 1409 & - & - & - & - & 0,6 & - \\
\hline (E)- $\beta$-caryophyllene & 1424 & - & - & 3,8 & - & - & - \\
\hline (E)-ethyl cinnamate & 1434 & - & - & - & - & - & 26,8 \\
\hline germacrene-D & 1480 & - & - & 1,1 & - & - & - \\
\hline$\delta$-cadinene & 1516 & - & - & 1,5 & - & - & - \\
\hline (E)-ethyl p-methoxy cinnamate & 1719 & - & - & - & - & - & 64,1 \\
\hline
\end{tabular}

Order of elution, retention indices (RI) and pourcentages are given on apolar column (BP-1). Investigated plants: 1: Illicium verum, 2: Agastache rugosa, 3: Ocimum gratissimum, 4: Michelia balance, 5: Cinnamomum cassia, 6: Kaempferia galanga

\subsection{Ocimum gratissimum L. essential oil, source of eugenol}

Ocimum gratissimum from Lamiaseae. The analysed sample is characterised by the predominance of eugenol (83\%) [synonym: 2-methoxy-4-allylphenol, 1-hydroxy-2-methoxy-4allylbenzene]. We noticed that the other components present at a content which allows their 
identification by ${ }^{13} \mathrm{C}$-NMR are all sesquiterpenes: (E)- $\beta$-caryophyllene, $\alpha$-copaene, $\delta$-cadinene and D-germacrene. Eugenol is widely used in pharmacy, perfumery, cosmetic and agribusiness (meats, sausages and sauces) due to its strange and pleasant smell of clove. The essential oil of Ocimum gratissimum, that possess an important antibacterial activity, was widely studied and several chemical compositions have been reported. Concerning the two more important compositions, one is dominated by eugenol and the other by thymol [11 - 13]. Our sample, that belongs to the first composition, is similar to that reported by Dung et al (eugenol, 74\%), also from Vietnam. It is also similar to the eugenol rich oils (32-90\%) reported by Lawrence from China, USSR, India, Madagascar, Taiwan, North America and from unspecified origin. However, the chemical composition of our sample differed from those of the oils from Rwanda, Cuba, Bangladesh, Benin and Sao-Tome and Principe, characterised by a high content of thymol (35-60\%). Otherwise, our sample is also different to the other samples reported in the literature with unusual chemical compositions: 2 samples from Brazil, respectively dominated by methyleugenol/eugenol and by $\mathrm{p}$-cymene/(E)- $\beta$-farnesene/thymol; one sample characterised by $\beta$-caryophyllene/eugenol/ $\beta$-elemene (unspecified origin); some compositions dominated by linalool, citral or ethyl cinnamate have been also reported.

\subsection{Michelia balance (DC) Dandy essential oil, source of safrole}

We analysed a sample of essential oil obtained from the aerial parts of Michelia balance (Magnoliaceae). Six compounds, amounting for 97\% of the global composition, were identified. Safrole [synonym 4-allyl-1,2-methylenedioxybenzene, 3,4-methylenedioxyallylbenzene] is the major component $(85 \%)$. The five other important components $(1.4-4.8 \%$ each) are all monoterpenes. Safrole possesses a smell similar to that of sassafras and it is widely used as flavour (drinks, chewing-gums), in pharmaceuticals (tooth pastes) and in the manufacture of detergents (soaps). The chemical composition of our sample is similar to those reported by Dung et al] for essential oils obtained from seeds and pulp of fruits from Vietnam. The last oils contained also safrole (73 and 70\%, respectively) together with methyleugenol (19 and 24\%, respectively) not present in our sample at a content sufficiently high to be identified by ${ }^{13} \mathrm{C}$ NMR. However, the investigated sample differed drastically from those of trunk (camphor $24 \%$ ), bark (camphor $16 \%$, safrole $15 \%, \beta$-caryophyllene $16.0 \%$ and elemicine $14 \%$ ) and leaves (elemicine $46.3 \%$ and $\beta$-caryophyllene $16.9 \%$ ) which exhibited a higher content of terpenes.

\subsection{Cinnamomum cassia Presl essential oil, source of (E)-cinnamaldehyde}

Cinnamomum cassia Presl. from Lamiaseae was introduced since a long time in Vietnam were it is cultivated in the mountainous regions particularly for its cork which can be harvested when the tree is $8-10$ years old. The cork oil contains $60-75 \%(E)$-cinnamaldehyde [synonym $=(E)$ 3-phenylpropenal]. In the investigated samples of this study, the content of (E)-cinnamaldehyde reached up to $90 \%$ of the composition of the oils extracted from cork, stems and trunk of Cinnamomum cassia. In the sample whose composition is reported in the table 1, we noted the occurrence, obviously at low level of cinnamyl alcohol an d the corresponding acetate, as well as borneol, a monoterpene alcohol, coumarin, a compound scarcely found in essential oils and which may result from the cyclisation of 3-phenylprop-2-enoic acid. Due to its strong spiced odour, E-cinnamaldehyde is used as a precious ingredient in perfumery. The composition of the investigated sample is close to that of the essential oil, also of Vietnamese origin, reported by Nguyen Thi Tam et al. Such a composition dominated by E-cinnamaldehyde is extensively reported in the literature and reviewed by Lawrence: although E-cinnamaldehyde is always the main component, its content varied from 55 to $97 \%$ of the whole composition of the essential oils, depending of the part of the plant hydrodistilled (leaves, branches or cork) as well as the origin of the plant. E-cinnamaldehyde is associated to benzaldehyde, coumarin, 2methoxycinnamaldehyde or sometimes, sesquiterpenes. 
2.6 Kaempferia galanga L. essential oil, source of (E)- Ethyl para-Ethoxycinnamate and (E)- Ethyl cinnamate

Kampferia galanga (Zingiberaceae) is a tropical scarcely found in the wild in Vietnam. The plant is cultivated in India an in Vietnam and is used as spice. In the folk medicine, the plant is known to facilitate digestion. The essential oil is extracted from rhizomes. The investigated sample was characterised by the occurrence of Ethyl (E)-cinnamate and overall its paramethoxylated derivative, Ethyl (E)-para-methoxycinnamate, the two compounds accounting for 37 et $64 \%$ of the composition of the essential oil, respectively. The chemical composition of that sample is in agreement with those reported in the literature.

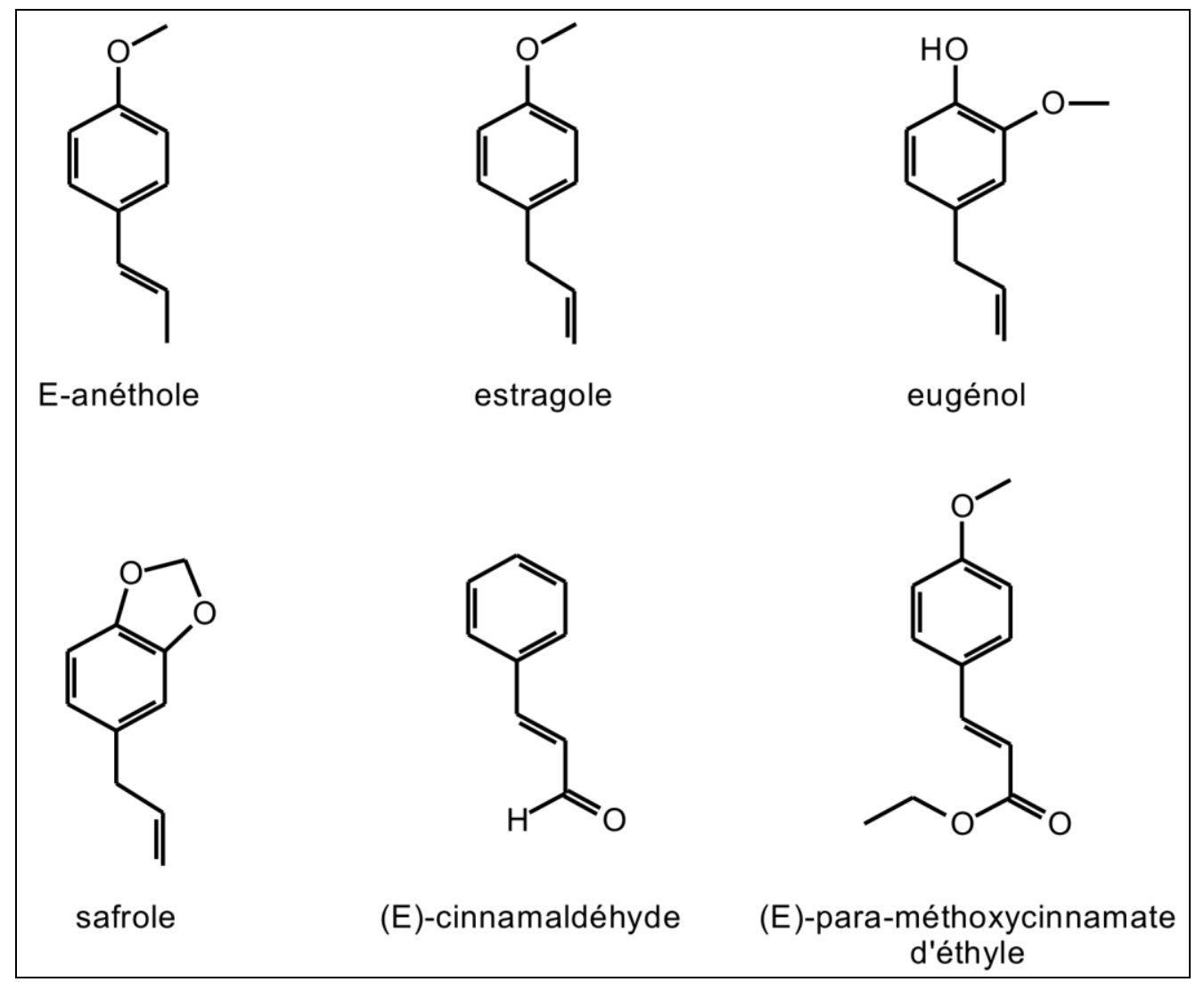

Fig. 1: Structure of the major components identified in essential oils from Vietnam.

\section{EXPERIMENTAL}

\subsection{Analytical GC}

GC analysis was carried out with a Perkin-Elmer Autosystem apparatus equipped with two flame ionisation detectors, and fused-silica capillary columns $(50 \mathrm{~m} \times 0.22 \mathrm{~mm}$ i.d., film thickness $0.25 \mu \mathrm{m}$ ), BP-1 (polydimethylsiloxane) and BP-20 (polyethyleneglycol). The oven temperature was programmed from $60^{\circ} \mathrm{C}$ to $220^{\circ} \mathrm{C}$ at $2^{\circ} \mathrm{C} / \mathrm{min}$ and then held isothermal $(20$ min); Detector temperature: $250^{\circ} \mathrm{C}$; Injector temperature: $250^{\circ} \mathrm{C}$ (injection mode: split $1 / 60$ ). 
Carrier gas: helium $(0.8 \mathrm{ml} / \mathrm{min})$. Injected volume: $0.5 \mu 1$ of a solution of $50 \mu 1$ of the oil diluted in $350 \mu 1$ of $\mathrm{CCl}_{4}$.

\subsection{GC/MS Analysis}

GC-MS analysis: The samples were analyzed with a Perkin Elmer Turbo mass detector, directly coupled to a Perkin Elmer Autosystem XL equiped with fused-silica capillary columns (50 $\mathrm{m} \times$ $0.22 \mathrm{~mm}$ i.d., film thickness $0.25 \mu \mathrm{m}) \mathrm{BP}-1$ (polydimethylsiloxane) and Rtx-WAX $(60 \mathrm{~m} \times 0.25$ $\mathrm{mm}$ i.d., film thickness $0.25 \mu \mathrm{m}$, polyethyleneglycol). Ion source temperature: $150^{\circ} \mathrm{C}$; Energy ionization: $70 \mathrm{eV}$; Electron ionization mass spectra were acquired oven the mass range $35-350$ Da. Split: 1/80. Other GC conditions were the same as described under GC. GC-MS analyses were carried out on both columns.

\section{3 ${ }^{13}$ C-NMR Analysis}

All NMR spectra were recorded on a Bruker AC 200 Fourier transform spectrometer operating at $50.323 \mathrm{MHz}$ for ${ }^{13} \mathrm{C}$, equipped with a $10 \mathrm{~mm}$ [or $5 \mathrm{~mm}$ ] probe, in $\mathrm{CDCl}_{3}$, with all shifts referred to internal TMS. ${ }^{13} \mathrm{C}$-NMR spectra were recorded with the following parameters: pulse width (PW), $5 \mu \mathrm{s}$ [or $3 \mu \mathrm{s}$ ] (flip angle $45^{\circ}$ ); acquisition time, $1.3 \mathrm{~s}$ for $32 \mathrm{~K}$ data table with a spectral width (SW) of $12500 \mathrm{~Hz}$ (250 ppm); CPD mode decoupling; digital resolution 0.763 $\mathrm{Hz} / \mathrm{pt}$. In a typical procedure, $200 \mathrm{mg}$ [or $70 \mathrm{mg}$ ] of the essential oil were diluted in $2 \mathrm{ml}$ [or 0.5 $\mathrm{ml}$ of $\mathrm{CDCl}_{3}$. The number of accumulated sca ns was $3000-6000$ for each sample, depending on the quantity of the oil available. Exponential line broadening multiplication $(\mathrm{LB}=1 \mathrm{~Hz})$ of the free induction decay (FID) was applied before Fourier transformation.

\subsection{Identification of Components}

Identification of the individual components was based: (i) on comparison of their GC retention indices (RI) on apolar and polar columns, determined relative to the retention times of a series of $n$-alkanes with linear interpolation ('Target Compounds' software of Perkin-Elmer), with those of authentic compounds or literature data, (ii) on computer matching with a laboratory made mass spectral library and commercial libraries and comparison of spectra with literature data, (iii) on comparison of the signals in the ${ }^{13} \mathrm{C}$-NMR spectra of the selected samples with those of reference spectra compiled in the laboratory spectral library, with the help of a laboratory-made software.

\section{CONCLUSIONS}

In the course of the French - Vietnamese program (Coopération décentralisée Région Corse Provinces du Nord - Viêt-Nam), our two groups worked on more of fifty aromatic plants from Vietnam: selection of plants, sampling, harvest, extraction of essential oils, analysis by several complementary techniques, detailed study with or without fractionation on column chromatography, chemical variability, .... Among these plants, we selected a dozen which produced an essential oil dominated by a single component. The essential oil may be considered as a potential source of that natural compound. We have compared our results with those reported in the literature from Vietnam or from other origin.

Acknowledgement: The authors are indebted to the Collectivités territoriale de Corse, the Ministère des Affaires Etrangères and the Caisse des Dépôts et Consignations for financial support (Programme de coopération décentralisée Corse - Vietnam) and the Société Montier (Ghisonaccia Corsica) for a research grant. The author thanks very much to the collaborateurs: Tran Huy Thai, Ninh Khac Ban, Nguyen Thi Phuong Thao, Joseph Casanova, Alain Muselli, Ange Bighelli, Vincent Castola,... for their contribution in the work. 


\section{REFERENCES}

1. Arctander, S. (1960), Perfume and Flavor Materials of Natural Origin, Elizabeth NJ, USA.

2. Bauer, K., Garbe, D., and Surburg, H. (1990), Common fragrance and flavor materials, VCH Publishers, New York.

3. Chalchat, J.C., Muhayimana, A., Habimana, J.B., and Chabard, J.L. (1997), Aromatic Plants of Rwanda. II. Chemical Composition of Essential Oils of Ten Eucalyptus Species Growing in Ruhade Arboretum, Butare, Rwanda, J. Essent. Oil Res., 9, p. 159.

4. Chalchat, J.C., Moudachirou, M., and Yayi E. (1997), Composition chimique d'huiles essentielles d'origine béninoise : Ocimum basilicum, O. canum et $O$. gratissimum L., Rivista italiana EPPOS, numero special, p. 551.

5. Dung, N.X., Loi, D.T., Hung, D.T., and Leclercq, P.A. (1991), Chemical composition of the oil of Blumea lanceolaria (Roxb.) Druce from Vietnam, J Essent. Oil Res., 3, pp. 285286.

6. Dung, N.X., Cu, L.D., Thai, N.H., Moi, L.D., Hac, L.V., and Leclercq, P.A. (1996), Constituents of the leaf and flower oils of Agastache rugosa (Fisch. et Mey) O. Kuntze from Vietnam, J. Essent. Oil Res., 8, pp. 135-138.

7. Dung, N.X., Tham, N.T., Khien, P.V., Quang, N.T., Le, H.T., and Leclercq, P.A. (1997), Characterization of the Oils from Various Parts of Talauma gioi Aug. Chev. (Magnoliaceae) from Vietnam, .J Essent. Oil Res., 9, pp. 119-121.

8. Nguyen Xuan Dung, Pham Van Khien, Do Duc Nhuan, Tran Minh Hoi, Ninh Khac Ban, Leclercq P. A., Muselli A., Bighelli A., and Casanova J. (1999), Composition of the Seed oil of Hibiscus abelmoschus L. (Malvaceae) Growing in Vietnam. J. Essent. Oil Res., 11, pp. 447-452.

9. Guenther, E. and Althausen, D. (1949), The Essential Oils, The constituents of essential oils., Vol. 2, Florida.

10. Guenther, E. (1972), The Essential Oils, History-Origin plants-Production-Analysis., Vol. 4, Florida.

11. Lawrence, M.B. (1995), Litsea Oil in Essential Oils, 1981-1987, 11, Allured Publishing Corporation, Carol Streanl.

12. Lawrence, B. (1995), Essential Oils, Agastache rugosa, 1988-91, 192, Allured Publishing Corporation, Carol Stream.

13. Lawrence, B., Essential Oils, Cymbopogon martinii, 1988-92, 81; 1981-87, 237.

14. Lawrence, B., Essential Oils, Eucalyptus citriodora, 1988-92, 2; 1981-87, 187; 1979-80.

15. Lawrence, M.B. (1995), Litsea Oil in Essential Oils, 1992-1994, 66, Allured Publishing Corporation, Carol Stream.

16. Lawrence, B. (1995), Essential Oils, Cinnamomum cassia, 1992-94, 163; 1978, 1,13; 19761977, 10,22, Allured Publishing Corporation, Carol Stream.

17. Lawrence, B., Progress in Essential Oils, Ocimum basilicum, Perfum. \& Flavor., 1995, 20, $35-37$

18. Lawrence, B. (2002), Progress in Essential Oils, Ocimum gratissimum, Perfum. \& Flavor., 27(1), 42-46.

19. Lawrence, B. (2003), Progress in Essential Oils, Illicium verum, Perfum. \& Flavor., 28(6), pp. 56-75. 
20. Lesueur, D., Ninh Khac Ban, Bighelli, A., Muselli, A., and Casanova, J. (2005), Analysis of the root oil of Fokienia hodginsii (Dunn) Henry et Thomas (Cupressaceae) by GC, GC/MS and ${ }^{13} \mathrm{C}$ - NMR. Flavour Fragr. J., in press.

21. Nguyen Thi Phuong Thao, Nguyen Thi Thuy, Tran Minh Hoi, Tran Huy Thai, Muselli, A., Bighelli, A., Castola, V., Casanova, J. (2004), Artemisia vulgaris L. from Vietnam: Chemical variability and composition of the oil along the vegetative life of the plant. $J$ Essent. Oil Res., 16, pp. 358-361:

22. Tomi, F. and Casanova, J. (2000), Contribution de la RMN du carbone-13 à l'analyse des huiles essentielles. Ann Fals Exp Chim 93(952), pp. 313-330.

23. Verlet, N. (1993), Overview of the Essential oils Economy, Acta Horticulturae, 333, pp. 65-72. 